Supporting information

\title{
Homogeneous and Real Super Tough Multi-bond Network Hydrogels Created through a Controllable Metal Ion Permeation Strategy
}

\author{
Xiao-Ying Liuł, Hao Xu†, Li-Qin Zhang, Ming Zhong, and Xu-Ming Xie* \\ Laboratory of Advanced Materials (Ministry of Education), Department of Chemical \\ Engineering, Tsinghua University, Beijing 100084, China \\ *Corresponding author.E-mail:xxm-dce@mail.tsinghua.edu.cn
}



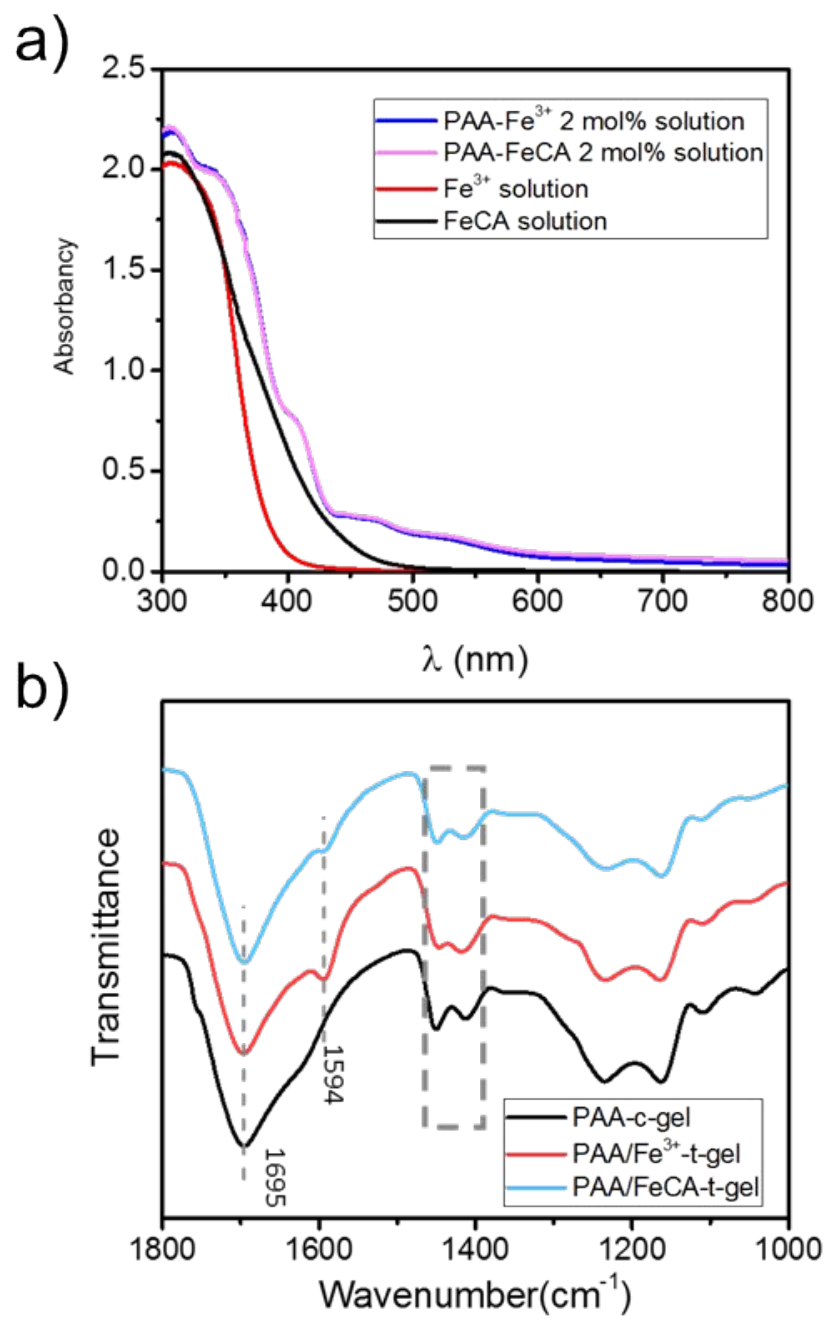

Figure S1. a) UV-vis spectra of $\mathrm{Fe}\left(\mathrm{NO}_{3}\right)_{3}$ solution $\left(0.0028 \mathrm{~mol} \mathrm{~L}^{-1}\right)$, FeCA solution $(0.0028$ mol L-1), PAA-Fe ${ }^{3+}$ solution (1 wt $\%$ PAA with $\left.0.0028 \mathrm{~mol} \mathrm{~L}^{-1} \mathrm{Fe}\left(\mathrm{NO}_{3}\right)_{3}\right)$ and PAA-FeCA solution ( $1 \mathrm{wt} \%$ PAA with $\left.0.0028 \mathrm{~mol} \mathrm{~L}^{-1} \mathrm{FeCA}\right)$; b) FTIR spectra of dried samples of chemical crosslinked PAA hydrogels (0.05 mol\% BIS), PAA/Fe ${ }^{3+}$-t-gel (F2CA0) and PAA/FeCA-t-gel (F2CA1) 
a)

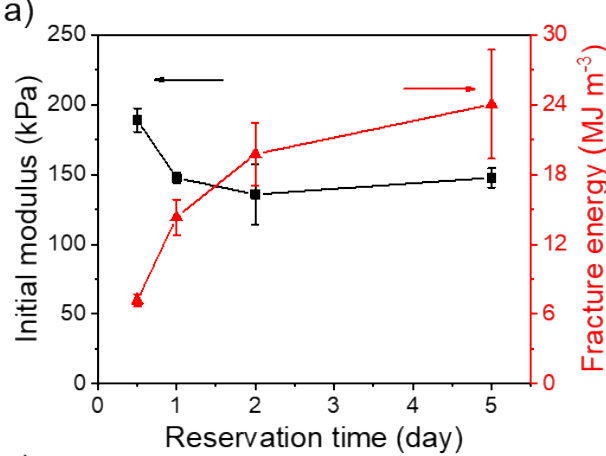

c)

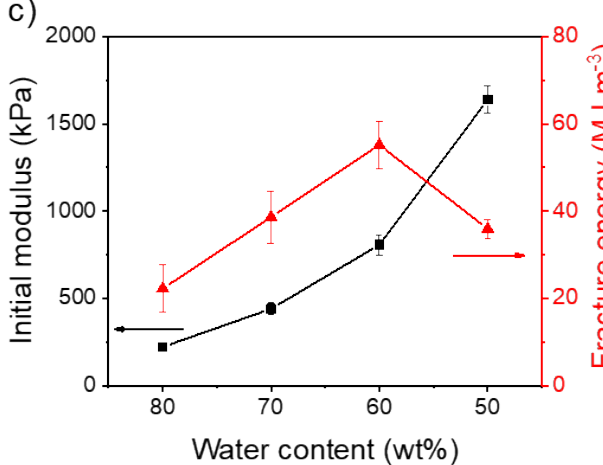

b)

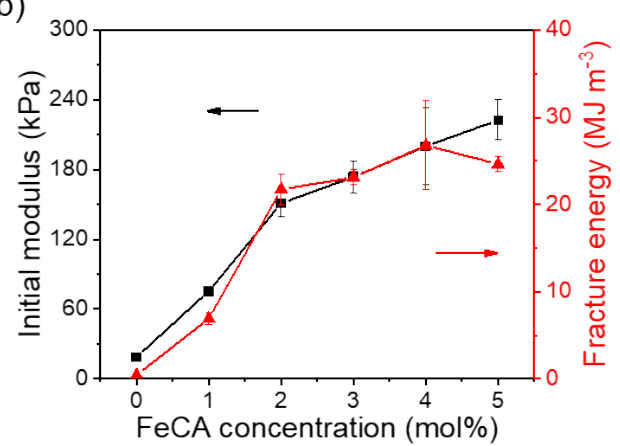

d)

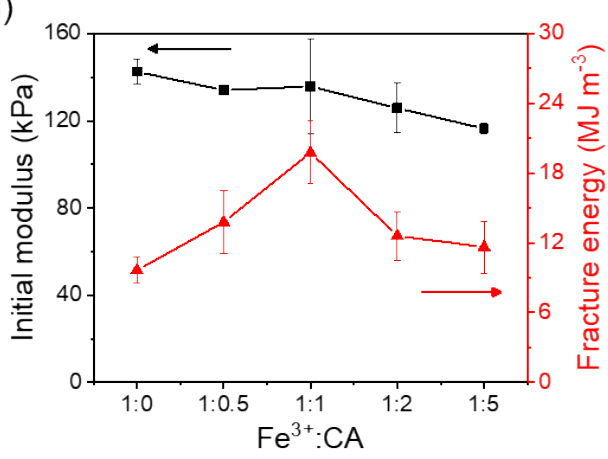

Figure S2. a) The changes of elastic modulus and fracture energy of F2CA1 gels as a function of reservation time. b) The changes of elastic modulus and fracture energy of FxCA1 gels as a function of FeCA concentration. c) The changes of elastic modulus and fracture energy of F5CA1 gels as a function of water content. d) The changes of elastic modulus and fracture energy of F2CAy gels as a function of the ratio of $\mathrm{Fe}^{3+}$ to $\mathrm{CA}$.

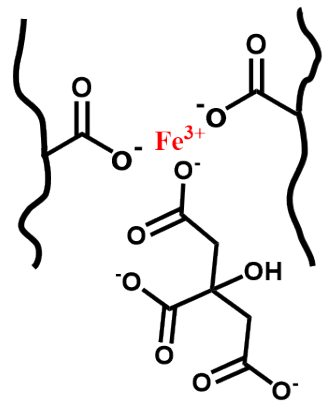<smiles>CCC(CC)C(=O)O[18O]C(=O)C[C@@H](O)C(=O)O</smiles><smiles>CCCC(CC)C(=O)O[Ga]1OC(=O)C(O)C(=O)OC(=O)C1C(=O)O</smiles>

Figure S3. By changing PAA-CA ratio, three different $\mathrm{PAA}-\mathrm{CA}-\mathrm{Fe}^{3+}$ coordinates can be formed. The formation of different coordinates has a great impact on mechanical properties of the MBN hydrogels. 


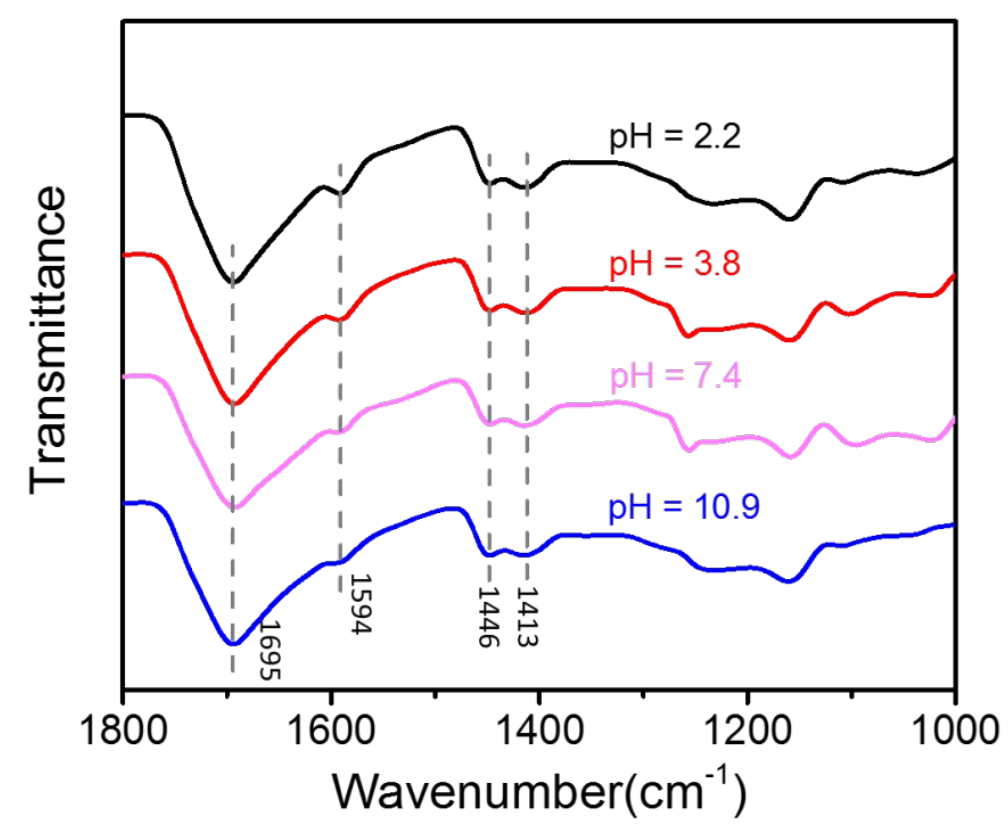

Figure S4. FTIR spectra of PAA/FeCA-t-gels with different $\mathrm{pH}$.

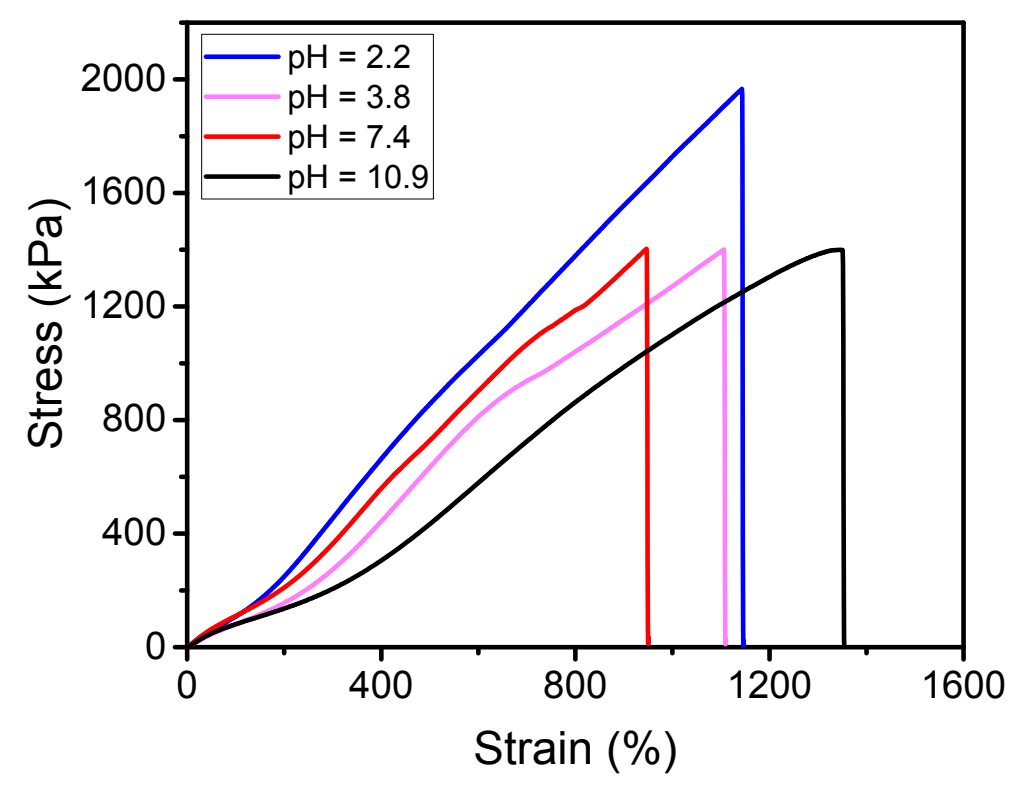

Figure S5. The tensile stress-strain curves of PAA/FeCA-t-gels with different $\mathrm{pH}$ (re-swelled F2CA1 gels with water content of $80 \mathrm{wt} \%$ ). 